\title{
Aromatase inhibitor therapy for endometrial stromal sarcoma - two-centre experience
}

\author{
Krystyna Serkies ${ }^{1}$, Anna Abacjew-Chmyłko² ${ }^{2}$ Magdalena Wieczorek-Rutkowska ${ }^{3}$, Rafał Pęksa ${ }^{4}$ \\ ${ }^{1}$ Department of Oncology and Radiotherapy, Medical University of Gdansk, Poland \\ ${ }^{2}$ Department of Gynecology, Oncology and Gynecologic Endocrinology, Medical University of Gdansk, Poland \\ ${ }^{3}$ Regional Center of Oncology COPERNICUS, Gdansk, Poland \\ ${ }^{4}$ Department of Pathology, Medical University of Gdansk, Poland
}

\begin{abstract}
Objectives: Endocrine therapy is the recommended systemic treatment for steroid receptor positive endometrial stromal sarcoma (ESS). There is no current consensus on the optimal hormonal therapy for ESS. The literature offers several reports on advanced/recurrent/metastatic ESS patients treated with progestins, whereas data on the efficacy of aromatase inhibitors are scarce.

Material and methods: We retrospectively identified cases treated for ESS with aromatase inhibitors at our institutions. There were five patients with advanced or unresectable recurrent estrogen, progesterone and androgen receptor-positive ESS, treated with aromatase inhibitors: letrozole or anastrozole (at a daily dose of $2.5 \mathrm{mg}$ and $1 \mathrm{mg}$, respectively), as first-line endocrine therapy in all but one case treated following progression with megestrol acetate.

Results: Disease stabilization was achieved in four cases (80\%), including two with long-term progression-free survival for up to 10 years attained under letrozole treatment, and one case after prior progestin treatment. During therapy, no substantial toxicity was observed.

Conclusions: Aromatase inhibitors as first- or second-line endocrine treatment achieve disease control in most steroid receptor positive ESS. Our series of cases is evidence of aromatase inhibitors efficacy as long-term endocrine treatment option for ESS patients.
\end{abstract}

Key words: endometrial stromal sarcoma; endocrine therapy; aromatase inhibitors

Ginekologia Polska 2018; 89, 11:607-610

\section{INTRODUCTION}

Endometrial stromal tumors are rare entities, comprising approximately $<1 \%$ of all uterine malignancies. Currently, malignant stromal tumors are subdivided into endometrial stromal sarcoma (ESS - previously known as low-grade endometrial stromal sarcoma) and high-grade/undifferentiated forms, which are distinguished by clinical behavior, histologic appearance, immunohistochemical features and chromosomal translocations [1,2]. CD10 was the most commonly used immunohistochemistry marker for ESS. Unlike non-ESS, a highly aggressive sarcoma with poor prognosis, ESS is generally a slow-growing malignancy with good prognosis, with an indolent clinical course, but with a high tendency for late recurrences. Advanced age and increased tumor size were found to be associated with decreased survival in large retrospective cohort of ESS [3]. Almost 80\% of ESS express estrogen (ER) and progesterone receptors $(\mathrm{PgR})$. Moreover, in most cases of ESS, the intratumoral immunohistochemical expression of gonadotropin releasing hormone receptor ( $\mathrm{GnRH}-\mathrm{R})$ as well as androgen receptor (AR) and aromatase was demonstrated $[4,5]$. The predictive value of these markers has not been determined to date. As far as steroid receptor positive tumors are concerned, hormonal therapy, mainly with progestins, has been shown to be an effective treatment for advanced ESS, which improves long-term survival.

\section{Objectives}

There is no current consensus on the optimal hormonal therapy for ESS. Due to the rarity of this tumor, no large-scale 
cohort studies or prospective studies regarding endocrine treatment have been conducted, with most of the available reports being case reports and small series. We present two-center experience with aromatase inhibitors (Als) for ESS, based also on a small study group.

\section{MATERIAL AND METHODS}

A retrospective search of all patients treated with Als for ESS was undertaken. A total of 5 consecutive patients with unresectable pelvic/abdominal steroid receptor positive ESS treated with Als in two centers since 2007 were identified (Tab. 1). Letrozole (4 patients) and anastrozole were administered at the standard daily dose of $2.5 \mathrm{mg}$ and $1 \mathrm{mg}$, respectively. Three patients, including two with late recurrent disease, underwent exploratory re-laparotomy, and two, with residual ESS, were treated postoperatively. Two patients with recurrence were previously misdiagnosed as having benign conditions. Als were administered as first-line endocrine therapy in all but one case with local progression after two years of megestrol acetate therapy.

Treatment response was assessed by the pelvis and abdomen computerized tomography (CT) performed every 3-6 months (sometimes less often). Tumor response was determined using RECIST criteria.

\section{RESULTS}

Disease stabilization with both Als was achieved in four cases (80\%) and, based on repeated control pelvis and abdomen CT imaging, it lasts till now. All patients were alive at the time this manuscript was written. The progressed patient is administered chemotherapy, and is alive, 11 months since the beginning of Al therapy. During treatment with Als, no significant side effects were observed. Three patients complained about mild (Grade 2) myalgia (3 patients) and hot flashes (Grade 1 and 2) (2 patients). Nonetheless, all patients are in excellent general condition. Notably, two women including the oldest patient (case 2. and 5.) have got painless pelvic bone involvement.

Two patients (case 1. and 2.) got osteopenia at the beginning of the $\mathrm{Al}$ therapy. Bone mineral density testing was performed annually. Case 1, already receiving standard osteoporosis prophylaxis, presented bone density loss after three years of letrozole therapy initiation and was diagnosed with osteoporosis. Therefore, bifosfonate (alendronate) was added to vitamin D3 and calcium supplementation.

\section{DISCUSSION}

Approximately $40-50 \%$ of patients with ESS of the uterus develop recurrent disease, which typically presents as pelvis, abdomen or lung metastases. Ovarian preservation and high levels of proliferation, as measured by the Mitotic Activity Index, in ESS tumors defined according to the 2003 WHO criteria, were found to be predictive of recurrence [6]. Debulking surgery of recurrence should be considered, if possible. In unresectable disease, endocrine therapy is thought to be the treatment of choice since ESS is considered to be relatively radio- and chemo-therapy resistant. Under hormonal therapy, partial response (PR) or disease stabilization (SD) of ESS le-

Table 1. Patient characteristics and outcomes

\begin{tabular}{|c|c|c|c|c|c|c|c|}
\hline Case & $\begin{array}{l}\text { Age at } \\
\text { primary } \\
\text { TAH/BSO } \\
\text { [years] }\end{array}$ & $\begin{array}{l}\text { Diagnosis } \\
\text { after primary } \\
\text { TAH/BSO }\end{array}$ & $\begin{array}{l}\text { Interval from } \\
\text { primary } \\
\text { TAH/BSO to } \\
\text { recurrence }\end{array}$ & IHC profile of ESS tissue & $\begin{array}{l}\text { Site of } \\
\text { lesions at } \\
\text { letrozole } \\
\text { therapy }\end{array}$ & $\begin{array}{l}\text { Therapy } \\
\text { (another } \\
\text { systemic or } \\
\text { local therapy) }\end{array}$ & $\begin{array}{l}\text { Response/ } \\
\text { duration } \\
\text { [month] }\end{array}$ \\
\hline 1. & 53 & Adenosis $^{b}$ & $7 y$ & $\begin{array}{l}\mathrm{ER}+, \mathrm{PR}+, \mathrm{AR}+, \mathrm{CD} 10+, \mathrm{Ki} 67 \text { \& Desmin \& } \\
\text { ASMA focally }+, \mathrm{CD} 117-\text {, aromatase -* }\end{array}$ & $\begin{array}{l}\text { Abdomen, } \\
\text { pelvis }\end{array}$ & Letrozole & $\mathrm{SD} / 133+$ \\
\hline 2. & $30^{\mathrm{a}}$ & $\begin{array}{l}\text { Endolymphatic } \\
\text { Stromatosis }{ }^{b}\end{array}$ & $30 y$ & $\begin{array}{l}\mathrm{ER}+, \mathrm{PR}+, \mathrm{AR}+, \mathrm{CK} \& \mathrm{EMA} \& \mathrm{CD} 99 \& \mathrm{CD} 34 \& \\
\mathrm{BCl} 2+\text {, Desmin \& Ki67 focally +, aromatse -* }\end{array}$ & $\begin{array}{l}\text { Abdomen, } \\
\text { pelvis }\end{array}$ & Letrozole & $\mathrm{SD} / 127+$ \\
\hline 3. & 53 & ESS & 0 & $\begin{array}{l}\text { ER }+, \mathrm{PR}+, \mathrm{AR}+, \mathrm{CD} 10 \text { \& WT1 \& Wimentin }+ \text {, } \\
\text { CD34 \& Desmin \& SMA \& CKAE1/3 \& Cyclin D } \\
\text { focally }+, \text { Ki67 20\%, CD117 -, aromatase -* }\end{array}$ & $\begin{array}{l}\text { Abdomen, } \\
\text { pelvis }\end{array}$ & $\begin{array}{l}\text { Anastrozole } \\
\text { (pelvic RT; } \\
\text { 30Gy/10 fraction) }\end{array}$ & $\mathrm{SD} / 26+$ \\
\hline 4. & 63 & ESS & $1.5 \mathrm{y}$ & $\begin{array}{l}\text { ER +, PR +/-, AR +, CD10 +, CD117 \& CD34 \& } \\
\text { SMA \& EMA \& Desmin \& S100 \& CKAE1/AE3 \& } \\
\text { Synaptofizine - , aromatase -* }\end{array}$ & $\begin{array}{l}\text { Abdomen, } \\
\text { pelvis }\end{array}$ & Letrozole & PD \\
\hline 5. & 37 & ESS & 0 & $\begin{array}{l}\mathrm{ER}+, \mathrm{PR}+, \mathrm{AR}+, \mathrm{CD} 10 \text { \& Cyclin D1 \& WT1 +, } \\
\mathrm{CKAE} 1 / 3+/-, \mathrm{CD} 117 \text { \& SMA \& Desmin \& } \\
\text { Inhibin \& H-caldesmon -, Ki67 20\%, } \\
\text { aromatase -* }\end{array}$ & Pelvis & $\begin{array}{l}\text { Letrozole (after } \\
\text { megestrol)*** }\end{array}$ & $\mathrm{SD} / 15+$ \\
\hline
\end{tabular}

TAH/BSO, total abdominal hysterectomy and bilateral salpingo-oophorectomy; ESS — endometrial stromal sarcoma; IHC — immunohistochemistry; ER - estrogen receptor; PR — progesterone receptor; AR — androgen receptor; SD — stable disease; PD — progressive disease; ${ }^{a}$ — after primary surgery she was not prescribed estrogen-containing hormone replacement therapy; ${ }^{b}$ - after re-operation due to pelvic/abdominal mass, the slides from the uteri resected earlier in both patients were reviewed and ESS was confirmed in both tumors; * using CYP19/aromatase polyclonal antibody (1: 25 dilution, LS-B3021, LifeSpan BioSciences, Inc.); **megestrol as adjuvant therapy was administered due to PT4N1 ESS (bladder infiltration) with R1 resection 
sions were typical, however complete response (CR) was also observed. No particular drug, dose, or regimen of endocrine treatment in ESS has been found to be superior. Several studies have demonstrated long-term benefits of progestins, including megestrol acetate and medroxyprogesterone acetate (MPA). Despite abnormal weight gain, hot flashes and swelling related to glucocorticoid activity, the side-effects of a long-term progestin therapy include increased risk of severe depression and thromboembolic complications. Because of these side effects, the third generation Als (letrozole, anastrozole and exemestane) have been considered as an alternative endocrine treatment for ESS. Als are medications which interfere with the aromatase enzyme, which is responsible for the conversion of testosterone and androstenedione into estrogen, established in endocrine therapy for breast cancer. Owing to the rarity of ESS, data on the efficacy of Als for ESS are scarce. PubMed database identified articles with a total of approximately 50 cases described in detail since 2001, treated with aminoglutethimide, anastrozole, letrozole and exemestane (Tab. 2) [7-24]. Als were used as first-line or second-line (or later-line) treatment, salvage after prior chemotherapy or adjuvant therapy after complete resection of the metastatic lesions. Clinical benefit ( $C R+P R+S D)$, frequently long-term, was reported in almost all patients. Under non-steroid Al letrozole, the most frequently used compound, objective response which lasted from 9 to 124 months, including 12 PR and nine CR among 27 cases, was reported [9-11, 19, 20, 23]. In the Yamaguchi et al., series of 5 patients, CR with letrozole was obtained in two cases with advanced or recurrent pelvic/abdomen ESS for 96 and 87 months, SD for 10 and 46 months also in two subjects, and PR in the remaining one patient (with 1 preserved ovary) who received letrozole plus GnRH analog and minodronate for lung metastases [23]. To the best of our knowledge, this was the only study with aromatase expression assessment; in all cases it was greater than $80 \%$ positive, with moderate intensity. Among our series of patients with negative aromatase expression ESS treated with non-steroidal Als, the two cases with late relapsed ESS achieved SD with letrozole for more than 10 years. This is the longest reported ESS treatment with Als. Anastrozole has shown clinical benefit, most frequently after progestins, for hormonally sensitive ESS tumors [7, 8, 18, 22]. In another study which included patients with metastatic ESS, positive outcomes with non-steroidal Als (letrozole or anastrozole) in both, first- ( 11 cases) and second- (7 cases) line treatment was demonstrated [25]. The authors stated that all available hormonal options should be used in sequence in the management of ESS. In the anecdotal reports on exemestane, a well-tolerated type I steroidal irreversible $\mathrm{Al}$, a prolonged response, even in case of progression after prior Al treatment, was observed [8, 22].

Based on different mechanisms of action and the lack of cross-resistance between different Als, hormonal manipulations including continuing different $\mathrm{Al}$ therapy despite the failure of prior $\mathrm{Al}$, or the addition of $\mathrm{GnRH}$ analogues to $\mathrm{Al}$ in ESS tumors that are ER+ seems to be justified. Moreover, the use of $\mathrm{GnRH}$ analogues alone or in combination with MPA, as well as a single modality treatment with progestins or antiandrogen therapy, seems valid. Chemotherapy should be limited to patients with hormone-unresponsive tumors.

Good tolerance of Als was reported in all abovementioned studies. Nevertheless, beside adverse events such as myalgia and arthralgia, the long-term use of this class of medications results in postmenopausal vasomotor symptoms, vaginal dryness and osteoporosis.

In this series, besides ER and PR expression, aromatase and AR expression were assessed as well. To our knowledge, only four previous studies evaluated AR expression in ESS, but none assessed aromatase at the same time. The question whether aromatase and AR, in addition to the ER and PR status, may help guide hormonal ESS therapy needs further elucidation.

Our study is not without limitations, chief among them a small number of the presented cases. However, the rarity of the disease, especially with advanced/recurrent/metastatic ESS patients treated with Al therapy, is the reasons why no large-scale cohort studies for hormonal treatment may be performed.

Table 2. Studies with aromatase inhibitors (Als) in endometrial stromal sarcoma

\begin{tabular}{|c|c|c|c|c|c|c|c|}
\hline \multirow{2}{*}{ Form of AI } & \multirow{2}{*}{$\mathbf{N}$} & \multirow{2}{*}{ Line } & \multicolumn{4}{|c|}{ Response } & \multirow{2}{*}{ References } \\
\hline & & & CR & PR & SD & PD & \\
\hline Letrozole & $\begin{array}{l}17^{\mathrm{a}} \\
10\end{array}$ & $\begin{array}{l}\text { 1st } \\
\text { 2nd }\end{array}$ & $\begin{array}{l}6 \\
3\end{array}$ & $\begin{array}{l}9 \\
3\end{array}$ & $\begin{array}{l}1 \\
3\end{array}$ & $\begin{array}{l}1 \\
1\end{array}$ & $\begin{array}{l}{[9,10,11-13,16,17,20,23,24]} \\
{[8,10,14-17,19,21,22]}\end{array}$ \\
\hline Anastrozole & $7^{b}$ & 2nd & 1 & 1 & 4 & 1 & {$[7,8,18,22]$} \\
\hline Exemestane & 2 & $\begin{array}{l}\text { 2nd } \\
\text { 4th }\end{array}$ & - & 1 & 1 & - & {$[8,22]$} \\
\hline Aminoglutethimide & 1 & $1 s t$ & 1 & - & - & - & [19] \\
\hline
\end{tabular}

CR — complete response; PR — partial response; SD - stable disease; PD — progressive disease; ${ }^{\text {a } ~-~ o n e ~ c a s e ~ w a s ~ t r e a t e d ~ w i t h ~ l e t r o z o l e ~ f o r ~} 8$ months followed by anastrozole [9]; ${ }^{\text {b }}$ - including one case treated with anastrozole after medroxyprogesterone acetate for 14 years 


\section{CONCLUSIONS}

Our results support the efficacy of Als as first- and second-line endocrine treatment for recurrent unresectable steroid receptor positive ESS. Based on the currently available literature and considering the efficacy and the favorable toxicity profile, Als should be recommended as first-line hormonal therapies for advanced receptor positive ESS.

\section{Conflict of interests}

The authors declare that they have no competing interests.

\section{Author contribution statement}

KS conceived the study, wrote the manuscript, contributed to the literature review, and was involved in the management of the patients, AA-Ch and MW-R were involved in the management of the patients and participated in literature review, RP made the pathological diagnoses. All authors read and have approved the final version of the manuscript.

\section{REFERENCES:}

1. Conklin C, Longacre T. Endometrial Stromal Tumors. Adv In Anat Pathol. 2014; 21(6): 383-393, doi: 10.1097/pap.0000000000000046.

2. Serkies K, Pawłowska E, Jassem J. Systemic therapy for endometrial stromal sarcomas: current treatment options. Gin Pol. 2016; 87(8): 594-597, doi: 10.5603/gp.2016.0051.

3. Seagle BL, Shilpi A, Buchanan S, et al. Low-grade and high-grade endometrial stromal sarcoma: A National Cancer Database study. Gynecol Oncol. 2017; 146(2): 254-262, doi: 10.1016/j.ygyno.2017.05.036.

4. Reich O, Regauer S. Aromatase expression in low-grade endometrial stromal sarcomas: an immunohistochemical study. Mod Pathol. 2004; 17(1): 104108, doi: 10.1038/sj.modpathol.3800031, indexed in Pubmed: 14631363.

5. Roy M, Kumar S, Bhatla N, et al. Androgen Receptor Expression in Endometrial Stromal Sarcoma. Int J Gynecol Pathol. 2017; 36(5): 420-427, doi: $10.1097 /$ pgp.0000000000000353.

6. Feng W, Hua K, Gudlaugsson E, et al. Prognostic indicators in WHO 2003 low-grade endometrial stromal sarcoma. Histopathology. 2013; 62(5): 675-687, doi: 10.1111/j.1365-2559.2011.04115.x.

7. Alkasi Ö, Meinhold-Heerlein I, Zaki R, et al. Long-term disease-free survival after hormonal therapy of a patient with recurrent low grade endometrial stromal sarcoma: a case report. Arch Gynecol Obstet. 2008; 279(1): 57-60, doi: 10.1007/s00404-008-0631-6.

8. Altman $A D$, Nelson $G S$, Chu $P$, et al. Uterine sarcoma and aromatase inhibitors: Tom Baker Cancer Centre experience and review of the literature. Int J Gynecol Cancer. 2012; 22(6): 1006-1012, doi: 10.1097/IGC.0b013e31825b7de8, indexed in Pubmed: 22740004.

9. Bréchot $\mathrm{JM}$, Kamboucher $\mathrm{M}$, Brauner $\mathrm{M}$, et al. Pulmonary metastases from endometrial stromal sarcoma may benefit from hormone therapy. Rev Mal Respir. 2007; 24(1): 69-72, indexed in Pubmed: 17268368.

10. Dahhan T, Fons $G$, Buist $M$, et al. The efficacy of hormonal treatment for residual or recurrent low-grade endometrial stromal sarcoma. A retro- spective study. Eur of Obstet \& Gynecol Reprod Biol. 2009; 144(1): 80-84, doi: 10.1016/j.ejogrb.2009.02.005.

11. loffe YJ, Li AJ, Walsh CS, et al. Hormone receptor expression in uterine sarcomas: Prognostic and therapeutic roles. Gynecol Oncol. 2009; 115(3): 466-471, doi: 10.1016/j.ygyno.2009.08.014.

12. Krauss K, Bachmann $C$, Hartmann JT, et al. Management of late recurrence of a low-grade endometrial stromal sarcoma (LGESS): treatment with letrozole. Anticancer Res. 2007; 27(5B): 3477-3480, indexed in Pubmed: 17972504.

13. Leunen $M$, Breugelmans $M$, Sutter PhDe, et al. Low-grade endometrial stromal sarcoma treated with the aromatase inhibitor letrozole. Gynecol Oncol. 2004; 95(3): 769-771, doi: 10.1016/j.ygyno.2004.07.063.

14. Maluf FC, Sabbatini P, Schwartz L, et al. Endometrial stromal sarcoma: objective response to letrozole. Gynecol Oncol. 2001; 82(2): 384-388, doi: 10.1006/gyno.2001.6238, indexed in Pubmed: 11531300.

15. Nakamura K, Nakayama K, Ishikawa $M$, et al. Letrozole as second-line hormonal treatment for recurrent low-grade endometrial stromal sarcoma: A case report and review of the literature. Oncol Lett. 2016; 12(5): 3856-3860, doi: 10.3892/ol.2016.5186, indexed in Pubmed: 27895740.

16. Pink D, LindnerT, Mrozek A, et al. Harm or benefit of hormonal treatment in metastatic low-grade endometrial stromal sarcoma: single center experience with 10 cases and review of the literature. Gynecol Oncol. 2006; 101(3): 464-469, doi: 10.1016/j.ygyno.2005.11.010, indexed in Pubmed: 16368128.

17. Ryu $\mathrm{H}$, Choi YS, Song IC, et al. Long-term treatment of residual or recurrent low-grade endometrial stromal sarcoma with aromatase inhibitors: A report of two cases and a review of the literature. Oncol Lett. 2015; 10(5): 3310-3314, doi: 10.3892/ol.2015.3674, indexed in Pubmed: 26722331.

18. Shoji K, Oda K, Nakagawa S, et al. Aromatase inhibitor anastrozole as a second-line hormonal treatment to a recurrent low-grade endometrial stromal sarcoma: a case report. Med Oncol. 2010; 28(3): 771-774, doi: 10.1007/s12032-010-9511-6.

19. Spano JP, Soria JC, Kambouchner M, et al. Long-term survival of patients given hormonal therapy for metastatic endometrial stromal sarcoma. Med Oncol. 2003; 20(1): 87-93, doi: 10.1385/MO:20:1:87, indexed in Pubmed: 12665689.

20. Sylvestre V, Dunton C. Treatment of Recurrent Endometrial Stromal Sarcoma with Letrozole: A Case Report and Literature Review. Horm Cancer. 2010; 1(2): 112-115, doi: 10.1007/s12672-010-0007-9.

21. Tzakas E, Liu S, Todd RW, et al. Hormonal therapy with letrozole prior to surgical management of recurrent metastatic low-grade endometrial stromal sarcoma (LGESS). Obstet Gynecol. 2009; 29(8): 778-779, doi: 10.3109/01443610903165552.

22. Wolfe H, Bunch K, Stany M. Prolonged response to exemestane following multiple surgical resections and hormonal therapies in a patient with recurrent endometrial stromal sarcoma. Gynecol Oncol Rep. 2016; 15: 4-6, doi: 10.1016/j.gore.2015.07.008.

23. Yamaguchi $M$, Erdenebaatar $C$, Saito $F$, et al. Long-Term Outcome of Aromatase Inhibitor Therapy With Letrozole in Patients With Advanced Low-Grade Endometrial Stromal Sarcoma. Int Gynecol Cancer. 2015. 25(9): 1645-1651, doi: 10.1097/igc.0000000000000557.

24. Yang K, Shin J, Jung J, et al. A Case of Metastatic Low-Grade Endometrial Stromal Sarcoma Treated with Letrozole after Ovarian Ablation by Radiotherapy. Cancer Res Treat. 2015; 47(4): 958-962, doi: 10.4143/crt.2014.154.

25. Thanopoulou E, Aleksic A, Thway K, et al. Hormonal treatments in metastatic endometrial stromal sarcomas: the 10-year experience of the sarcoma unit of Royal Marsden Hospital. Clin Sarcoma Res. 2015; 5(1), doi: 10.1186/s13569-015-0024-0. 